\title{
¿QUÉ ES UN PSICÓLOGO CLÍNICO?: EN TORNO A LA PREPARACIÓN, COMPETENCIAS $Y$ DESARROLLOS DE UNA PROFESIÓN
}

\author{
Amparo Belloch Fuster \\ Catedrática de Psicopatologia \\ Especialista en Psicologia Clínica
}

\section{RESUMEN}

El objetivo del articulo es reflexionar acerca de diversos aspectos que afectan a la formación de los psicólogos clínicos, con especial referencia a nuestro entomo. Para ello se revisan los principales hitos histónicos relacionados con el surgimiento y la consolidación de la psicologia clínica, en tanto que actividad profesional especializada de la psicologia, asi como su situación actual en los contextos universitanio y sanitario españoles. Se debate después sobre algunas amenazas relacionadas con el desempeño profesional de los psicólogos clínicos, y que se derivan de la consagración del modelo de Boulder como paradigma de la formación de los psicólogos clínicos. Por último, se examinan algunos de los problemas que en un futuro cercano se pueden plantear como consecuencia de la creciente especialización y diversificación de la psicología clínica.

Palabras clave: PSICOLOGÍA CLÍNICA; FORMACIÓN EN PSICOLOGIA CLIF NICA; LICENCIATURA EN PSICOLOGIA.

Correspondencla: Facultad de Psicología, Universidad de Valencia. Avda. Blasco Ibañez 21. Valencia-46010 (España). Teléfono: 96 3983439. Fax: 96 3864669. Correo-e: Amparo.Belloch uv.es. 


\section{SUMMARY}

The aim of this paper has been to offer a personal view about several issues related to the training of clinical psychologists, with a special reference to our context. For this purpose, the seminal hystorical facts that promoted the birth of the clinical psychology are reviewed, as well as the current situation of the clinical psychology in the Spanish university context, and in the Public Health System. After that, some weaknessness and threats to the training of clinical psychologists as they are derived from the Boulder training model, are examined and discussed. Finally, some reflections are devoted to the problems that the increased diversification and complexity of clinical psychology are setting out to the training of clinical psychologists.

Key words: CLNICAL PSYCHOLOGY; TRANNG IN CLINICAL PSYCHOLOGY; GRADE IN PSYCHOLOGY.

\section{EPÍLOGO INTRODUCTORIO}

Todo to ignora quien nada duda (Conde de Rebollado).

Estas líneas las escribo cuando el artículo que tienen ante sus ojos ya está redactado, pero al mismo tiempo quieren ser una introducción al mismo. Cuando el Prof. Pelechano me pidió que escribiera un trabajo sobre los requisitos para la formación de los psicólogos clínicos, me parecí́ algo relativamente fácil de hacer, pues desde hace unos cuantos años estoy involucrada en esa tarea e incluso tengo escritas algunas cosas al respecto (Belloch, 1997, 2003; Belloch e Ibáñez, 1989; Belloch y Olabarría, 1994). El problema vino cuando me puse a pensar qué contenidos y qué estructura dar a este artículo para no repetir lo ya dicho en otros lugares $y$ momentos. $Y$ eso me llevó a instalarme en una enorme duda acerca de cómo conciliar tres aspectos: lo que suponía que se esperaba que dijera, lo que en realidad queria decir en este momento, y cómo decirlo. He dicho duda y lo reitero: Sigo sin saber si al final he 
conseguido llegar a expresar lo que desde mi punto de vista constituyen requisitos necesarios para la formación de los psicólogos clínicos, no tengo nada claro que los asuntos que en este momento más me preocupan, tengan interés para otros y en especial, para el colectivo de psicólogos clínicos, y tampoco sé si he llegado a expresarme con claridad.

Con ánimo de intentar establecer algún orden argumental y no abundar más de lo necesario en la duda, el texto se organiza en cuatro apartados: el primero es un breve recordatorio histórico acerca del surgimiento de la psicología clínica, y su función es la de intentar situarnos en los orígenes de nuestra identidad, pues como dijo el poeta, quien pierde el conocimiento sobre sus origenes, pierde la identidad. El segundo pretende ser un resumen del estado actual de la cuestión, es decir, de cómo se está produciendo en nuestro país el entrenamiento y formación de los psicólogos clínicos, cuáles son los cauces establecidos para ello, cuáles sus contenidos y objetivos. El tercero es una reflexión crítica sobre la consideración tradicional y aceptada del modelo de formación del psicólogo clínico como un científico-aplicado. El cuarto y último pretende ser una recapitulación de todo lo dicho con la intención de mirar al futuro.

\section{RECORDANDO EL AYER}

"Ouien mira to pasado, lo porvenir advierte" (Lope de Vega)

Cuando se habla del nacimiento de la Psicología Clínica suelen citarse una fecha, 1896, y un nombre, Lightner Witmer, fundador de la primera Clínica Psicológica en la Universidad de Pensilvania. Desde el punto de vista histórico es ésta una fecha indiscutible; y, como dijo Garfield (1974), si hay alguien que merece el título de fundador de la Psicología Clínica, ese hombre es Witmer. Pero, ¿por qué surgió en ese lugar, en ese momento, y con esa denominación?.

Las respuestas son bastante bien conocidas y las he desarrollado en otro lugar (Belloch, 1997), de modo que únicamente haré aquí un breve recuerdo de ellas. Estaba surgiendo una nueva ciencia, la psicología, y estaba sucediendo en la Europa del último cuarto del siglo XIX. A mediados de ese siglo toda Europa estaba envuelta 
en una atmósfera de cambio como consecuencia de la introducción de los procesos de industrialización, que afectaba especialmente a las normas de convivencia social hasta entonces imperantes. Además, el respeto hacia los otros, la libertad del individuo, la igualdad entre las personas, la solidaridad, y. en definitiva, los nuevos valores sociales que a finales del siglo anterior habían inspirado la Revolución Francesa, habían calado hondo y se habían extendido como un reguero de pólvora por prácticamente todo el Continente.

En esa atmósfera, la ciencia experimenta también cambios notables que se pueden sintetizar en dos aspectos: primero, la adopción de un cambio de mentalidad, según el cual la observación natural (al modo Hipocrático) y el pensamiento reflexivo (al modo filosófico), dejan paso a la observación controlada y a la necesidad de predecir de un modo fiable el curso de los acontecimientos. El escepticismo, el relativismo y el mecanicismo son las características dominantes de la "nueva ciencia". La posibilidad de experimentar con la realidad, o sea, de intervenir activamente en ella y no solo de observarla pasivamente, se convierte en la marca de contraste de la autentica actividad científica, contrapuesta a la reflexión filosófica. Segundo, la implicación de los nuevos científicos en el mundo social en que viven: el científico adquiere conciencia de su poder para influir en los cambios sociales. Pinel, Tuke, Todd, Itard, o Dix, fueron algunos buenos ejemplos de ello. Pues bien: es ésta atmósfera la que hace posible el surgimiento de nuevas ciencias: en Alemania, la Psicología con Wilhelm Wundt, en Inglaterra la Antropología con James Prichard, y en Francia la Sociología con Auguste Comte.

Pero Wundt no es el único nombre al que debemos recurrir para reconstruir adecuadamente las raíces históricas de la Psicologia Clínica: F. Brentano, F. Galton, J.McKeen Cattell, y la amplia tradición psicodinámica resultan seguramente mucho más importantes en este aspecto, como han señalado prácticamente todos los historiadores (Reisman, 1976).

Estas raíces de la Psicología Clínica explican su nacimiento pero además proporcionan, en mi opinión, algunas de las claves importantes de su desarrollo posterior, incluyendo las dudas y los debates presentes en esta disciplina: desde la diversidad de modelos teóricos explicativos de los trastornos mentales (los basados en la tradición 
científico-experimental de Wundt versus los derivados de la línea inaugurada por Brentano) hasta la diversidad de roles del psicólogo clínico (testing, consejo, psicoterapia, investigación básica, investigación aplicada, etc), pasando por los debates sobre su formación cientifico-experimental versus profesional-aplicada. Sobre estas cuestiones, en especial sobre sus repercusiones actuales, volveré más adelante.

Todos estos acontecimientos estaban sucediendo en un lugar y un tiempo específicos: la Europa del siglo XIX. Sin embargo, el nacimiento "oficial" de la Psicologia Clínica se produjo en EEUU. Las razones de este traslado geográfico son muchas, pero todas guardan alguna relación con un aspecto muy caracteristico de la cultura norteamericana: su concepción eminentemente práctica, aplicada, de la cultura y la actividad científicas, que conlleva la necesidad de poner la ciencia al servicio de la sociedad. Como dijo Korchin (1983, p.5) “ El enfoque funcionalista y pragmático de la psicología americana, proporcionaba un terreno especialmente receptivo a la clínica y a otras psicologias aplicadas. El americano tenía poca paciencia para una psicología que diseccionaba hasta en sus más mínimos detalles las estructuras de la mente (...) asi como para una psicologia que especulaba en exceso sobre la naturaleza final de la mente humana"

Así pues, la Psicología Clínica surge como una disciplina aplicada de la Psicología y lo hace de la mano de un americano, Lightner Witmer, que había estudiado con Cattell y que, siguiendo los pasos de éste, acudió también al laboratorio de Wundt en Leipzig. Según Joseph Collins, Witmer describió la Psicología Clínica en su conferencia ante la American Psychological Association (APA) de 1896 en los siguientes términos: "La Psicología Clínica se deriva de los resultados que se obtienen a partir del examen individualizado de muchos seres humanos (....) la clinica psicológica es una institución pública abierta al servicio de la sociedad, a la investigación propia, y a la formación de los estudiantes".

A Witmer le debemos pues la creación de esta profesión, su denominación, y algunas de sus características distintivas. Sin embargo, como han dicho Bemstein y Nietzel (1980, p. 44), 'Witmer puso en marcha la Psicología Clínica, pero tuvo muy poco que ver 
con su desarrollo". Las causas de la escasa relevancia de Witmer en el desarrollo y la consolidación de la Psicología Clínica, hasta el punto de ser considerado por algunos como una mera anécdota histórica (Watson, 1953), son diversas pero hay una especialmente significativa, según Reisman (1976): Witmer hizo poco o ningún caso a los desarrollos que se estaban produciendo en otros ámbitos de la psicologia, especialmente en los relacionados con el diagnóstico (por ej., el test de Binet), los tratamientos psicológicos (por ej., el psicoanálisis), y la extensión de la clínica psicológica a los problemas mentales de los adultos.

Esta expansión de la psicologia clínica se asocia, ya desde el principio, a debates y problemas relacionados con la formación del psicólogo clínico. La demanda social de estos nuevos profesionales empezaba a ser importante y la única organización profesional de psicólogos entonces existente, la American Psychological Association (APA), parecía no darse por enterada. De hecho, cualquiera podía autocalificarse como psicólogo clínico y no existian reglas que garantizaran su formación. En 1917 un grupo de psicólogos decidió formar una sociedad independiente (The American Association of Clinical Psychologists) para solucionar este caos', y aunque duró poco (volvió al seno de la APA dos años después), era el primer indicio de las "peleas" que iban a producirse en el futuro acerca de la formación y el rol de los psicólogos clínicos.

En todo caso, hacia el final de la $1^{2} \mathrm{GM}$ ya no habia muchas dudas acerca de la realidad de la Psicología Clínica como actividad profesional propiamente dicha, esto es, con entidad propia. El factor más influyente para su rápida expansión fue seguramente el de la evaluación y medida de las capacidades mentales, en especial de la inteligencia. Pero este factor tuvo una consecuencia, todavía vigente en muchos sentidos: la consideración del rol del psicólogo clínico como un experto en evaluar las múltiples facetas de la actividad y la experiencia humanas, de modo que los psicólogos clínicos no solo

1. Resulta cuanto menos llamatwo que en Esparta hayamos tenido que esperar casi un siglo para poder regular de un modo precteo la tormactón de los psicologos clínicos a travós del sistema interno-residente (el modelo PIA). 
utilizaban instrumentos especialmente diseñados para evaluar la inteligencia, sino que además empezaron a desarrollar instrumentos para medir la personalidad, los intereses y las emociones. Muchos de estos tests fueron desarrollados a partir de los planteamientos psicoanalíticos europeos, que habían llegado a calar muy hondo en la Psicología Clínica norteamericana: no olvidemos tampoco que los planteamientos freudianos resultaban muy atractivos para estos psicólogos clínicos, en parte porque eran los únicos que proporcionaban alguna explicación acerca de las relaciones que el individuo mantiene con su entorno. Y la Psicología Clínica necesitaba disponer de este tipo de explicaciones, que no le podian proporcionar, o no sabían cómo hacerlo, los planteamientos elementalistas y estructuralistas post-wundtianos en los que la psicologla europea segula estando más interesada.

Lo que sucedió a continuación es bien sabido por todos: se consolida la Psicología Clínica, se generaliza el uso de los instrumentos de evaluación y diagnóstico, y aunque la influencia psicodinámica se extiende a todos los ámbitos de la Psicología Clínica incluido el de la infancia, proliferan otros modelos y/o escuelas. La pregunta es por qué se produce esa proliferación de teorías. Hay varias respuestas. La más optimista, pero seguramente también la menos plausible, es que la psicología (y con ella, la psicología clínica) había avanzado mucho y el modelo dinámico se habfa quedado "pequeño". Este tipo de explicaciones endogámicas tienen algo de razón, pero son insuficientes porque olvidan algo que es una constante en el desarrollo de la psicología: la presión social como motor de crecimiento. $Y$ en este contexto, hay otra razón más cercana a la realidad y de la que podemos aprender mucho de cara al futuro. Como recuerda Stone (1985), una de las secuelas que tuvo la $1^{2} \mathrm{GM}$, fue la aparición de muchos casos de "neurosis de guerra" que ponían al descubierto las limitaciones de la psiquiatria, por aquel entonces casi exclusivamente biologista. Téngase en cuenta que este trastorno mental afectaba a hombres jóvenes, bien nutridos y hasta entonces sanos, que on muchos casos habian prestado sus servicios como voluntarios, y que nada tenían que ver con la legión de enfermos mentales que eran atendidos en los asylum, y que en su mayor parte perteneclan al lumpen-Proletariat. En consecuencia, 
no solo había que buscar nuevos modelos para explicar adecuadamente la ruptura que se había producido en las mentes de estos grupos de gente hasta entonces "normal", perteneciente además a las clases sociales que estaban manteniendo y financiando con su esfuerzo la maquinaria de la guerra, sino que además se ponía seriamente en cuestión la utilidad de los recursos asistenciales disponibles para atenderlos adecuadamente: los manicomios, y los tratamientos agresivos y en muchos casos invalidantes. En este contexto, la búsqueda de otros marcos de referencia alternativos al biologista se torna apremiante. $Y$ de todos los posibles, el psicodinámico era el más importante y mejor conocido.

Ahora bien: no se olvide que el modelo psicodinámico había surgido en el ámbito médico y, entre otras cosas, permitía ampliar el rango de intervenciones terapéuticas, extraordinariamente limitadas para los psiquiatras por ese entonces. Desde ahí cabe entender que en 1954 la Asociación Médica Americana reivindicara la psicoterapia -entendida en ese contexto como la práctica del psicoanálisis- como un procedimiento médico. $Y$, como han dicho Pilgrim y Treacher (1992), "la lógica consecuencia de esta toma de postura era que el psicólogo que practicara psicoterapia, lo haría de forma ilegal". La "guerra" entre dos profesiones afines, la psiquiatría y la psicología clínica, estaba servida. Pero lo que me interesa destacar aquí es otra cosa: los psicólogos clínicos necesitan desarrollar otros modos de psicoterapia alternativos al psicoanálisis. $Y$ bien entrados los años cincuenta, estos modos comienzan a hacerse bien visibles: desde las terapias breves (Rogers, Ellis, etc.), hasta la terapia y modificación de conducta, sólidamente asentada en el conductismo. $Y$ aquil comienza verdaderamente el despegue científico y profesional de la psicología clínica.

El conductismo es el primer gran modelo psicológico que abraza sin dudarlo los principios teóricos y metodológicos del programa positivista imperante en la ciencia. Era, además, un modelo fácilmente "transportable" al contexto clínico: permitía explicar, diagnosticar y tratar cualquier trastorno mental, sin exclusión, fuera cual fuese la edad en que éste se presentara, de forma individualizada o en grupo, dependiendo de la naturaleza del problema y de los objetivos del tratamiento. $Y$ sobre todo permitía hacer todo eso desde dentro 
de la Psicología, lo que evitaba enredarse en estériles disputas "territoriales" y epistemológicas con los psiquiatras.

Aparte de todos estos desarrollos, sin duda importantes, quiero resaltar aquí dos fechas y dos hechos que se encuentran intimamente relacionados con el propósito de este artículo: las famosas Conferencias de Boulder en 1949 y Chicago en 1965, que establecieron las pautas que en adelante iban a marcar las lineas directrices del entrenamiento profesional de los psicólogos clínicos, norteamericanos primero $y$, por extensión, de la mayoría de los países después. En ambas se proclama la necesidad de que el psicólogo clínico adquiera una formación práctica y/o aplicada de la psicología, sólidamente basada en los principios de la ciencia psicológica, lo que lleva a caracterizar a los psicólogos clínicos como "científicos-practicantes". Sobre este tema volveré más adelante. Abandono en este punto el breve recuerdo de la historia, para centrarme en el presente.

\section{EL AQUÍ Y AHORA: LA FORMACIÓN DE LOS PSICÓLOGOS CLÍNICOS.}

"Si cree usted que la educación es cara, pruebe con la ignorancia" (Derek Bok)

En nuestro país la implantación y desarrollo de la psicología clínica corre pareja con el desarrollo de los estudios de psicología en el ámbito universitario. Aun cuando los estudios de psicología están presentes ya desde los años veinte del siglo pasado, no es hasta bien entrada la década de los setenta cuando se puede hablar con propiedad de una cierta consolidación. Carpintero (1989) y Siguán (1978), entre otros, han expuesto de manera excelente $y$ pormenorizada el desarrollo de los estudios de psicología en España, por lo que no me detendré aquí en ello. Sólo quisiera indicar que desde el inicio mismo de los estudios de psicología, la psicología clínica se configura como una de las tres especialidades psicológicas aplicadas o profesionales (Belloch, 2003; Belloch y Olabarria, 1994). Baste como ejemplo recordar que ya en la Escuela de Psicología y Psicotecnia de la Universidad de Madrid, creada en 1953, se contemplaban las secciones de psicología clíníca, pedagógica, e industrial. De ahí que se exigiera a quienes quisieran matricularse en la Escuela estar en posesión de una Licenciatura universitaria, 
ya que su orientación fundamental era la preparación para la práctica de la psicología en alguno de estos ámbitos. De todos es reconocido que la Escuela fue el embrión del posterior desarrollo de la psicologia en el contexto universitario. Este desarrollo tuvo su lugar, primero, en las Facultades de Filosofía y Letras, para ir configurando un espacio propio y diferenciado ya en la década de los setenta. A mediados de esta década, la presencia de los estudios de Psicología en la Universidad Española experimenta un crecimiento espectacular, pasando de tener una representación simbólica de poco más de un centenar de estudiantes a finales de los sesenta, a registrar una matriculación de más de 13.000 alumnos a mitad de los setenta. A continuación haré un breve repaso de la presencia que ha tenido, tiene, y previsiblemente va a tener la Psicología Clínica en el contexto Universitario.

\section{La Psicología Clínlca en el contexto Universitario}

Los primeros planes de estudio de la Licenciatura se configuran en torno a un predominio de disciplinas consideradas de carácter teórico y metodológico (Psicología General, Fundamentos Biológicos del comportamiento, Bases sociales del comportamiento, Desarrollo a lo largo del ciclo vital, Estadística, Psicometria, etc.), a expensas de una representación comparativamente escasa y a menudo casi simbólica de aquellas otras que podrian considerarse como más directamente vinculadas con las aplicaciones prácticas de la Psicología como profesión, lo que como es natural afectaba a las materias "clínicas". Este panorama empieza a experimentar algunos cambios, más bien tímidos, con la introducción en algunas Universidades (de las que la de La Laguna es el ejemplo paradigmático) de contenidos prácticos con peso curricular oficial, acompañado del aumento de las materias "aplicadas" (Clínica, Educativa, Social/Industrial) en el segundo ciclo, ya sea mediante la creación de itinerarios específicos para cada una de ellas, ya mediante la intensificación de la carga docente de este tipo de materias.

Con la Ley de Reforma Universitaria de 1983 y sus posteriores desarrollos legislativos tiene lugar una profunda modificación de la 
estructura curricular en toda la Universidad Española y, en particular, de la Licenciatura en Psicología. Entre los más importantes desarrollos legislativos cabe citar, el Real Decreto de 1888/1984, según el cual la Psicología se aglutina (o se divide, según se mire) en 6 áreas de conocimiento que reproducen y consolidan el esquema diferenciador entre psicología básica o teórica y psicología aplicada: en el primer bloque se integran las áreas de Metodología, Básica, y Psicobiologia, y en el segundo las de Personalidad (en la que se incluye la Psicología Clínica), Evolutiva y de la Educación, y Social. Este Real decreto se complementa y amplía con el de Noviembre de 1990 que establece las directrices generales del título universitario de Licenciado en Psicologia, y según el cual el primer ciclo de 2 o 3 años deberá estar dedicado a enseñanzas básicas y de formación general, y un segundo ciclo de 2 años, pensado para profundizar en las posibles especializaciones profesionales, si bien se establece desde el inicio que sea cual fuere la especialización escogida por el estudiante, los estudios de Psicología conducirán a la obtención de un único titulo universitario oficial y de validez en todo el territorio nacional: Licenciado en Psicología. Y a partir de 1990 todas las Facultades de Psicología se involucran, una vez más, en la renovación de sus planes de estudios. Estos planes no han resultado tan coincidentes como cabria esperar, pues a nadie se le escapa que han sido más deudores de las correlaciones de fuerzas e intereses locales de todo tipo, que del debate epistemológico que, al menos en mi opinión, debiera haberse producido en torno a la Psicologia. Debate que refiere no solo a contenidos nucleares, sino también al modo de arbitrar una licenciatura generalista, la articulación de los contenidos teóricos con la aplicación de los mismos en la práctica, el contexto en el que debe desarrollarse dicha práctica, su finalidad, por no hablar de la demanda real de psicólogos en la sociedad, o de su formación posterior a la Licenciatura.

Es verdad que se han producido muchas coincidencias en lo que a los contenidos formales se refiere: así, los perfiles o itinerarios preprofesionales han sido y son básicamente los mismos en todas las Universidades, y entre ellos, la Clínica es una constante. Pero también lo es, me parece, que no hay acuerdo explícito alguno en cuanto las contenidos teórico-metodológicos que deben estar presentes de 
manera irrenunciable sobre la base de las evidencias cientifficas disponibles, la amplitud y profundidad de los contenidos a impartir, el modo de impartirlos, su articulación con las prácticas a realizar y el momento y el lugar en que éstas deben realizarse, el nivel de exigencia para considerar que el estudiante ha adquirido suficientemente los contenidos impartidos, la puesta en marcha efectiva de controles de calidad de las instituciones y los profesionales, y sobre todo, qué contenidos clínicos son básicos para cualquier futuro licenciado en psicologia y cuáles no lo son, o lo son en menor medida ${ }^{2}$. Por poner algún ejemplo: ¿por qué la psicopatología, aun considerándose troncal, tiene una representación significativamente menor en la licenciatura que las disciplinas relacionadas con el área de metodología? ¿es acaso menos básica o fundamental?. Oyendo a otro más reciente: ¿por qué a la psicologla clínica se le pone sistemáticamente el apellido "y de la salud"?.

Entiéndaseme: no pretendo opinar aquí sobre si este tipo de decisiones me parece bien, regular, o mal: lo que me preocupa es que se toman en ausencia de un debate explícito, amplio, y fundamentado, en el que los intereses de grupo, aunque legítimos, estén lo menos presentes posible. Lo que me preocupa es que la Universidad no haya promovido un estudio en profundidad sobre los

2. En más de una ocasión he escuchado que el principio y el derecho fundamental de la Libertad de Cátedra, impide imponer criteríos sobre el tipo de contenidos a impartir en la Universidad. Sobre la bese de tal principio, llegar a acuerdos sobre qué contenidos deben necesariamente impartirse en todas las Facultades ( $y$ aur en un mismo Departamento) al respecto de una materia concreta, resulta poco menos que imposible. Esto me parece simplemente una barbaridad: la libertad de catedra nada tiene que ver con el impartir lo que a cuakquiera de nosotros le parezca mejor, o más cómodo, o más interesante, o incluso más digerible y atractivo para los estudiantes. La consecuencia de este modo de entender las cosas la tenemos a la vista a diario: programas de asignaturas diferentes con contenidos que se solapan de menera abitraria, prolesores que debiendo impartir por ejemplo los fundamentos biológicos de los trastomos mentales imparten por el contrario los criterios diagnósticos de tal o cual manual, o los que en disciplinas consideradas "básicas" (atención, percepción, etc.) se dedican a explicar las patologías neuróticas, o los que al impartir algura materia clínica son incapaces de salirse de su manual, o no han tenido nunca la oportunidad ni el interés por trabajar con pacientes mentales, o explican exclusivamente aquella orientación teórica, aquel paradigma, aquella propuesta terapéutica que más les gusta sin molestarse siquiera en explicar por qué hicleron esa elección. 
cometidos y las competencias profesionales específicas de las diversas opciones profesionales de la psicología, y de la psicología clínica en particular. Así, da la sensación de que todo el mundo puede "ejercer" como psicólogo clínico, o de que la clínica está presente urbi et orbi, esto es, en cualquier actividad profesional de la psicología, lo que sugiere un desconocimiento profundo de los múltiples y varios desarrollos de la psicología clínica en los últimos veinte años, tanto desde el punto de vista conceptual como desde el profesional. Tengo la sensación, puede que equivocada, de que casi todos los psicólogos de este país se sienten capaces de diagnosticar y tratar adecuadamente cualquier problema de pareja, familiar, de grupo, de salud física, o cualquier trastorno mental que se les ponga por delante, ya sean psicólogos que desempeñan su trabajo en el ámbito educativo, en el de la empresa, e incluso en el de la investigación básica. Pero no conozco a ningún psicólogo clínico que ejerza como tal que se pronuncie sobre cómo se debe hacer una selección de personal, o una intervención educativa para mejorar el rendimiento y la adaptación escolar, ni mucho menos aún que lleven a cabo tales actividades, por poner sólo dos ejemplos.

Esta situación de indefinición de preparación y competencias profesionales, en la que aparentemente todos podemos hacer de todo, en especial cuando hablamos de psicología clínica, me trae a la memoria el ejernplo de Lysenko, el genetista ruso de la época de Stalin, que pensó que si cortaba el rabo de las ratas nada más nacer durante varias generaciones consecutivas, acabarian por nacer ratas sin rabo. Los excesos de esto que podríamos catalogar como voluntarismo social extremo, no solo no ayudan al progreso de una ciencia sino que, por el contrario, van en contra del mismo, porque son ciegos para reconocer que se está produciendo ese progreso. No todos podemos hacer todo (salvo que nos de igual si lo hacemos bien o no), por mucho que insistamos en ello, por mucho que persistamos en el error. Quien no es capaz de reconocer sus propios límites, no solo se daña a si mismo sino a la totalidad del colectivo al que pertenece. $Y$ en el caso de la psicología clínica, el daño además se propaga a un colectivo extremadamente vulnerable: los pacientes mentales. 
Es verdad que de esa carencia de debate y clarificación somos todos responsables, incluyendo por supuesto a los propios psicólogos clínicos, entre los que me incluyo. $Y$ también lo es que el surgimiento de la Licenciatura se ha producido prácticamente al mismo tiempo que toda una vorágine de desarrollos legislativos en torno a la reordenación de los estudios universitarios en España. Desarrollos que, además, han tenido lugar en un periodo temporal extraordinariamente breve (recuérdese que las primeras Facultades de Psicología aparecen a mediados de los setenta), y para el que se nos requería tomar decisiones casi de forma inmediata, lo que impedía, o dificultaba sobremanera, el necesario sosiego para llevar adelante un debate amplio, a partir del cual poder llegar a consensos aceptables y aceptados por la mayoria. Pero sobre todo, este estar permanentemente instalados en la urgencia, ha tenido una consecuencia que considero extremadamente negativa: la falta de tiempo para evaluar los efectos que estaban teniendo en la sociedad las decisiones que se iban adoptando. Es decir: ¿qué carencias en la formación recibida quedaban al descubierto cuando los recién licenciados se enfrentaban al mundo laboral?, ¿qué demandaba la sociedad a estos psicólogos?, ¿cuántos licenciados encontraban una ocupación acorde con sus intereses y su preparación?, ¿en qué ámbitos estaban desarrollando su actividad, y bajo qué controles de calidad lo hacían, aquellos que se dedicaban a la clínica?. Conocer el impacto que tiene una decisión determinada, es sin duda un criterio fundamental para introducir mecanismos correctores. Pero no hemos podido, o no hemos sabido, analizar de manera sisternática esta cuestión. Y cuando hemos conocido los resultados al respecto de algún estudio (por ejemplo, algunos llevados a cabo por el Colegio Oficial de Psicólogos), no hemos llegado a tenerlos en cuenta, o solo de manera tangencial y anecdótica.

De entre todas las carencias, destaca la escasa preocupación mostrada en general por la Universidad por la preparación para la competencia profesional, lo que es una queja habitual entre los recién licenciados que intentan incorporarse al mundo laboral, y como no se encuentran capacitados, deben buscar una preparación adicional por su cuenta, en muchos casos sin referentes ni criterios objetivos y extemos de calidad y, las más de las veces, nada baratos. 
Santolaya, Berdullas y Fernández (2002), lo han puesto también de manifiesto: "Los psicólogos se encuentran abocados a aumentar su nivel de competencia a través de una formación de postgrado seria y científicamente sólida, que se encuentre íntimamente relacionada con las necesidades sociales que demandan sus servicios. Esta formación debería, a su vez, llevar aparejada la existencia de una "marca" que identifique claramente a los profesionales capaces".

Ahora nos hallamos de nuevo inmersos en un proceso de cambio, marcado en esta ocasión por las exigencias del denominado Espacio Europeo de educación superior. Gran parte del esfuerzo de cambio y adaptación está siendo liderado por los representantes democráticamente elegidos por todos nosotros, los actuales Decanos de las Facultades, que han producido un documento de extraordinaria importancia bajo los auspicios de la ANECA. En ese informe se puede leer lo siguiente en el apartado de recomendaciones: "La Titulación debe hacer esfuerzos para mejorar la formación práctica durante los estudios. (....) debe fomentar el desarrollo de aquellas competencias claves que permita a los licenciados adaptarse a las necesidades del mercado laboral. Los planes de formación deben procurar el desarrollo de competencias profesionales flexibles que permitan la adaptación al mercado laboral." Consecuentemente con ello, se propone un practicum de 9 créditos ( 270 horas), a desarrollar en Centros profesionales, para que los estudiantes adquieran las siguientes competencias: "Conocer los distintos campos de aplicación de la Psicologia y tener los conocimientos necesarios para incidir y promover la calidad de vida en los individuos, grupos, comunidades y organizaciones en los distintos contextos: escolar, clínica y salud, trabajo y organizaciones y, comunitario". Estas competencias son idénticas a las que se contemplan para otras dos áreas (Evaluación y Diagnóstico, e Intervención y Tratamientos), y lo más notable es que su finalidad última, y por tanto es de suponer que la de cualquier psicólogo aplicado, reside en incidir y promover la calidad de vida.

Dejando a un lado el hecho de que este planteamiento significa, a mi entender, una redefinición profunda de cuáles son los cometidos de un psicólogo y, por extensión, del objeto de la psicologia como ciencia, que no entraré a valorar aqul, hay algo que me llama la 
atención en especial: el énfasis en la "adaptación al mercado laboral", coincidente en lo esencial con el párrafo que antes mencioné del escrito de Santolaya et. al., máximos representantes actuales del Colegio Oficial de Psicólogos ${ }^{3}$. Bienvenida sea esta coincidencia esencial, pues revela que algún proceso de retroalimentación se ha producido entre el mundo profesional-aplicado y el universitario. Pero no puedo dejar de manifestar también que me parece un énfasis excesivo. Una lectura maliciosa del propósito de una Licenciatura en la que, por sobre cualquier otra consideración, se enfatiza de tal modo la adaptación a las exigencias sociales, podría llevar a hacer pensar que es el mercado laboral el único legitimado para marcar las pautas de lo que debemos y podemos hacer, y no nuestras propias capacidades y desarrollos, nuestros intereses e inquietudes como científicos que creen que tienen algo nuevo que ofrecer a la sociedad. Por decirlo simple y llanamente: parecería que nuestro desarrollo debe estar marcado por las necesidades de adaptación, y no por la búsqueda de nuevos nichos ecológicos, dicho en términos neo-evolucionistas. Si un organismo vivo tiene como finalidad primordial la adaptación a los cambios que se producen fuera de él para sobrevivir, pero no se plantea además que debe ser un agente activo de cambio, de generación de nuevas oportunidades de crecimiento, de nuevos desarrollos adaptativos, sus expectativas de cara al futuro son más bien precarias y, por lo que a mí respecta, poco ilusionantes. Este es un camino peligroso, sobre el que deberíamos reflexionar bastante antes de darlo por bueno sin más. Está bien escuchar al mercado, saber qué demanda, y preparar a los profesionales ade-

3. Las referencias al Colegio de Psicologos son abundantes a lo largo de todo el documento, lo que sin duda revela un esfuerzo notable, y muy de agradecer por parte de los Decanos, de contar con la opinión del mundo "profesiona" de la Psicologla española en la elaboración de los futuros planes de estudio. No obstante, creo que además de este organismo, a cuyo mantenimiento todos colaboramos por imperativo legal, y cuyas competencias están claramente delimitadas por la legislación española al respecto de los colegios profesionales, la Universidad debería ampliar el marco de sus interlocutores, y de manera especiel, incluir a las sociedades cientificas, de libre elección por quienes participan en ellas, y que cuentan en muchos casos con un prestigio blen ganado y demostrable en el contexto nacional $\theta$ intemacional, ademés de una amplia tradición en vanios casos, para escuchar también sus opinlones. Al menos eso es to que se hace en los palses de nuestro entomo. 
cuadamente para responder satisfactoriamente a esa demanda. Pero no puede ser, o no debe, el único ni principal elemento a la hora de diseñar un curriculum académico, ni de establecer las Iineas maestras de la formación de los futuros profesionales de la psicologla clínica. Debe ser un elemento a tener en cuenta, pero no el punto de partida (ni el de llegada).

Mientras tanto, y por lo que a la psicología clínica se refiere, la propuesta de contenidos que se realiza en el citado documento de los Decanos reproduce básicamente el status quo actual, heredado de los primeros planes de estudio de los ochenta: un peso sustancialmente superior para las disciplinas básicas, a expensas de una representación menor de las más directamente vinculadas con el mundo profesional. Cierto es que en el documento citado se habla únicamente, como no podía ser de otro modo, de la reordenación de los futuros estudios de Licenciatura, que pasarán a denominarse de Grado, y que no capacitan de manera directa para el ejercicio laboral o profesional, a diferencia de to que viene sucediendo hasta la fecha. Esto significa que las competencias a adquirir para el ejercicio profesional de la psicología deben adquirirse a posteriori, a través de los estudios de Master, cuya elaboración, implantación, organización y financiación, quedan al arbitrio de la autonomía universitaria. $Y$ en esas estamos. Vamos a ver qué somos capaces de hacer.

\section{La Pslcología Clínica en el contexto del SIstema Nacional de Salud}

De forma casi paralela a la expansión de los estudios de Psicología, se produce la universalización de la prestación sanitaria a toda la población. La publicación en 1986 de la Ley General de Sanidad, por la que se crea el Sistema Nacional de Salud, heredero de la antigua Seguridad Social, concebido como el conjunto armónico y coordinado de los servicios de salud, sanciona el derecho universal y público de todos los ciudadanos españoles a recibir una prestación sanitaria de calidad. El propio Estado Español se convierte en garante de tal derecho, y es por tanto el responsable de establecer cuantos instrumentos y procedimientos sean necesarios para garantizar el 
derecho a la salud de los ciudadanos (Palacios, 2004). Entre esos procedimientos el estado escoge un modelo para formar a los profesionales sanitarios sobre los que va a recaer el peso de la atención sanitaria: el sistema de internado-residencia rotatoria, el conocido bajo las siglas MIR que era el imperante en Estados Unidos y gracias al cual se decla que la Medicina de ese Pals habla alcanzado un lugar de privilegio entre los paises del "primer mundo", y que ya estaba demostrando su utilidad desde mediados de los setenta en España.

El sistema MIR supuso, en la práctica, una ruptura con el modelo universitario tradicional, más anclado en una concepción térica que aplicada, y con pocos recursos, y en muchos casos mal gestionados, para la formación de especialistas sanitarios. El sistema garantizaba además el acceso libre y universal al proceso formativo de cualquier licenciado, ya que al mismo podían acceder quienes más conocimientos eran capaces de demostrar en un concurso público. Además, estos aprendices de especialista en tal o cual rama de la medicina, recibian un salario a la vez que una formación. Se trataba por lo tanto de un esquema muy alejado del hasta entonces imperante, con selecciones en muchos casos arbitrarias y elitistas, que los aspirantes tenían que superar para poder acceder a las escuelas de formación de especialistas ligadas las más de las veces al poder casi omnímodo de las cátedras de las Facultades de Medicina. Y además, en muchos casos tenían que pagar para formarse.

Pues bien: es en ese contexto en el que debemos situar a la Psicología Clínica, que desde su mismo inicio a finales del siglo XIX se concibió como una prestación sanitaria especializada de la psicología. $Y$, ya en nuestro contexto, en consecuencia con la Ley General de Sanidad española, la prestación sanitaria especializada de la Psicología Clínica debía ser reclamada por los psicólogos españoles como un derecho para todos los ciudadanos españoles. Si esto era así, resultaba entonces obvio que la Psicología Clínica no podía ni debía operar al margen de los procedimientos normativos y los desarrollos legislativos que regulan la formación sanitaria especializada en nuestro sistema sanitario (AEPCP, 2004a).

El primer paso en este camino nada fácil fue la instauración en 1993 a nivel del Estado del sistema PIR como via para la adquisición 
de una formación especializada en Psicología Clínica. Este ha sido un logro indudable de muchas personas e instituciones, $y$ ha permitido incluir la especialidad dentro del modelo y del marco legal por el que, desde 1978 (en normativa ampliada y ratificada en 1984), se rige la formación de especialistas sanitarios en nuestro país: el modelo de psicólogos internos-residentes, ublcados en instituciones sanitarias de la red sanitaria pública (o concertada). Desde entonces se han formado en psicología clínica por este sistema cerca de 900 psicólogos (sin contar los que hablan adquirido una formación análoga en años precedentes, a través de las convocatorias PIR puestas en marcha en diversas Comunidades Autónomas).

El segundo paso fue la creación legal de la especialidad, que se produjo con la publicación de un Real Decreto en 1998. Por desgracia, el mismo fue denunciado y recurrido en términos legales por diversas sociedades de psiquiatría y por el Colegio Oficial de Médicos, lo que supuso hacer explícito un largo proceso previo de resistencia a veces soterrada, a veces manifiesta, por parte de un grupo significativo de psiquiatras españoles a la creación de la psicología clínica como una especialidad sanitaria con características propias y no subordinada ni deudora de otras ya existentes, como la psiquiatría. Lo paradójico fue que hubo también algunas asociaciones de psicólogos, que ejerclan su actividad clínica en el ámbito privado, que se sumaron a la retahila de recursos legales. Pero afortunadamente, estos recursos no fueron ganados en los tribunales por sus proponentes y la especialidad siguió adelante. $Y$ ello se debió sin duda al esfuerzo colectivo y aunado del Colegio Oficial de Psicólogos y tres sociedades científicas directamente vinculadas con el desarrollo de la psicología clínica en España: la Asociación Española de Psicología Clínica y Psicopatología, compuesta por psicólogos clínicos, la Asociación Española de Neuropsiquiatria, que agrupa psicólogos clínicos, psiquiatras, y enfermeros especialistas en salud mental, y la Asociación Nacional de Psicólogos Internos y Residentes, que agrupa al ya afortunadamente numeroso colectivo PIR. Además de estas entidades, muchos psicólogos del mundo universitario y del profesional colaboraron denodadamente desde diversas instancias para presentar contraargumentos sólidos en contra de los recursos presentados. $Y$ en 
todos los casos, con un altruismo que es preciso destacar, reconocer, y aplaudir. En definitiva, conseguir que la Psicología Clínica formara parte del sistema sanitario español como especialidad con entidad propia y autónoma, al mismo nivel que el resto de las especialidades sanitarias, y a la que tuvieran acceso todos los ciudadanos que acuden al sistema sanitario público, no ha sido una labor precisamente fácil (AEPCP, 2004b; Olabarría, 2004).

EI Programa PIR actual se articula a lo largo de 3 años, y al mismo pueden acceder los licenciados en Psicologia o en alguna de las antiguas licenciaturas previas (Filosofía y Letras, Sección Psicología - División Filosofía y Ciencias de la Educación). Los objetivos generales de la formación son, básicamente, los que siguen (copio textualmente):

"Capacitar a los psicólogos clínicos en formación para (...): a) el desempeño de su profesión, desde una perspectiva de atención integral, cubriendo los niveles de promoción, prevención, asistencia y rehabilitación, (...) b) las tareas de evaluación, intervención, y tratamientos psicológicos, y (...) c) el ejercicio interdisciplinario que una concepción multidimensional del sujeto y de la salud, requieren. (....) al final de su período de formación, el psicólogo clínico deberá haber adquirido las siguientes habilidades:

Utilizar instrumentos y técnicas psicológicas para la identificación de los trastornos mentales y de los factores de riesgo asociados a ellos; uso adecuado de técnicas de entrevista psicológica; recepción y análisis de la demanda y establecimiento del adecuado plan de intervención clínica; técnicas de relación interpersonal y de trabajo en equipo; diagnóstico y evaluación psicológica de los trastornos mentales mediante técnicas de evaluación adecuadas y ateniéndose a sistemas de clasificación homologados; elaboración, aplicación y evaluación de programas de intervención, psicológica a nivel individual, familiar, grupal y comunitario; elaboración, aplicación y evaluación de programas de intervención psicológica en pacientes agudos y participación en la resolución de situaciones de crisis; elaboración, aplicación y evaluación de programas de intervención psicológica para la población infantil y adolescente; elaboración y aplicación de programas de rehabilitación y atención prolongados; deberá estar capacitado para participar en la programación de la coordinación con 
los dispositivos de la red asistencial y el adecuado conocimiento y utilización de los recursos sociales, educativos y comunitarios; deberá estar capacitado para participar en la programación de las actividades preventivas y de promoción de la salud, en coordinación con los Equipos Básicos de Atención Primaria; desarrollar programas de asesoramiento a otros agentes sociales no sanitarios; manejo de metodología y diseños de investigación clínica, social y epidemiológica en Salud Mental; realizar informes, certificados y peritajes psicológicos".

El programa de formación se articula en torno a un circuito de rotación por distintos dispositivos asistenciales de la red sanitaria pública. Estos dispositivos "han de tener un marco definido: una red sanitaria de servicios especializados acreditados a tal fin, lo que contribuirá a garantizar una mejor adecuación de la formación del perfil del especialista, que los avances cientificos y la progresiva transformación de la red asistencial y la atención hoy demandan. El circuito se caractenzará por estar compuesto de distintos servicios especializados de Salud Mental en un área ternitorial determinada, constituyendo entre si una unidad funcional". En este párrafo he subrayado un aspecto importante, con la intención de explicar en qué consiste, ya que no suele ser conocido por parte de quienes no están al tanto del proceso. Antes de reconocer a un equipo o un centro la capacidad para formar futuros especialistas en psicología clínica, se ha de documentar adecuada y extensamente que se tiene esa capacidad. Es decir, se tiene que demostrar que se dispone de los lugares y centros necesarios para que el futuro PIR adquiera su formación, asi como que hay profesionales psicólogos dispuestos a tutonizar y evaluar la calidad de la formación, la competencia y los conocimientos adquiridos por el PIR. Entonces, y solo entonces, la Comisión Nacional de la Especialidad informa favorablemente sobre la petición al Ministerio de Sanidad, que es quien finalmente concede o no la acreditación como centro para la formación de especialistas. Posteriormente, los centros acreditados son regularmente expuestos a auditorías por parte del Ministerio, a través de las cuales se comprueba el cumplimiento del programa, su calidad, y se propone el mantenimiento de la acreditación para la docencia o, por el contrario, su retirada. 
En cuanto a los dispositivos básicos del circuito y el tiempo minimo de permanencia en cada uno de ellos, el programa establece los siguientes: A) Unidad de Salud Mental Comunitaria, es decir, un centro de asistencia especializada en salud mental de carácter ambulatorio, que es el eje central de referencia para todo el proceso de formación. Estos centros deben contar como mínimo con programas de atención a la población infanto-juvenil, adulta y de tercera edad, además de disponer de programas estructurados de apoyo y coordinación con Atención Primaria, Servicios Sociales, etc. El tiempo de permanencia en esta unidad debe ser como mínimo de un año. B) Unidades de hospitalización psiquiátrica en hospitales generales o en su defecto, unidades de agudos en hospitales psiquiátricos, con espacios y equipos diferenciados. Estas unidades o servicios deben contar con programas de interconsultas, de enlace, y de coordinación con otros servicios del hospital. El tiempo minimo de formación en estas unidades es de 4 meses. C) Programas y/o Unidades de Rehabilitación especificamente configurados como tales, y que deberán contar con programas de rehabilitación y reinserción adecuadamente coordinados con Servicios Sociales. El tiempo de formación en estas unidades no deberá ser inferior a 6 meses.

Este programa es obviamente limitado en su alcance y objetivos, y su elaboración y definición son escasas, cuando no manifiestamente insuficientes y discutibles en especial por lo que se refiere a la definición que ofrece sobre la psicología clínica ("...una especialidad básica de la Psicologia que se ocupa de la conducta humana y los fenómenos psicológicos y relacionales en la vertiente salud-enfermedad de los seres humanos"). No obstante es preciso hacer una aclaración al respecto: el programa fue aprobado para su puesta en marcha por una Comisión promotora ${ }^{4}$ de la actual Comisión de la Especialidad, pero esta Comisión prácticamente no pudo participar en su elaboración. En realidad el programa habia sido diseñado y aprobado previamente por una comisión mixta (psiquiatras y psicólogos clínicos), que se vieron obligados a trabajar

4. Formada por profesionales de la práctica de la psicologia clínica en el sistema sanitario público (B.Olabarría, F. Vallejo, M.A.Garcia-Alvarez, J.Leal, M.Laviana), un representante del Colegio Oficial de Psicólogos (I. Carbonero), y tres de la Universidad (A.Avila, S. Lemos, y yo misma). 
contra corriente y soportando presiones de todo tipo, provenientes en su mayoria tanto de la Comisión Nacional de Psiquiatría como del mismo Ministerio de Sanidad, y que tenían como objetivo limitar al máximo las funciones y el desarrollo formativo de los futuros psicólogos clínicos. Y a pesar de todo ello, de todas las negociaciones, de todas las renuncias..... ila creación de la especialidad fue objeto de recurso!.

La actual Comisión Nacional de la Especialidad ha elaborado un nuevo programa, pendiente de aprobación desde hace 3 años, que amplía el proceso formativo a 4 años, especifica con claridad los objetivos, habilidades a adquirir, y actividades concretas a realizar en cada uno de los dispositivos asistenciales por los que habrán de adquirir su formación los futuros especialistas. Asimismo se contempla, por ejemplo, la obligatoriedad de realizar un trabajo de investigación (que puede ser la tesis Doctoral) sobre temas vinculados con la psicología clínica. El objetivo de la Psicología Clínica se define como "el desarrollo y la aplicación de los principios teóricos, métodos, procedimientos e instrumentos para observar, comprender, predecir, explicar, prevenir y tratar trastomos mentales, alteraciones $y$ trastornos cognitivos, emocionales $y$ comportamentales, malestar $y$ enfermedades en todos los aspectos de la vida humana, asi como la promoción de la salud y el bienestar personales y de la sociedad". Antes de su aprobación definitiva, el programa fue remitido a un grupo muy numeroso de protesionales, incluyendo el ámbito universitario, con el objetivo de recabar sus opiniones y sugerencias de cambio, a pesar de que la Comisión no dispone de presupuesto propio alguno para llevar a cabo esa tarea.

Como es natural el programa no es el optimo y es mejorable en muchos aspectos, al menos a priori. Pero seguramente, solo a partir de su puesta en funcionamiento real, podrán introducirse los cambios pertinentes. Para ello están previstos distintos mecanismos de evaluación de la calidad: desde las auditorias a las que anteriormente hice referencia (ya se han hecho algunas), a la realización de encuestas a todos los PIR (ya se han hecho varias ediciones), pasando por la comprobación de los contenidos incluidos en el Libro del Residente, diseñado para que cada PIR anote pormenorizadamente todas las actividades formativas realizadas, así como las carencias encontradas en su formación y/o en los centros por 
los que ha ido adquiriéndola. Este último instrumento, al igual que el nuevo programa de formación, todavla están pendientes de su aprobación definitiva por el Ministerio de Sanidad.

Uno de los aspectos que no está ni regulado ni apenas contemplado es el que se refiere a la formación continuada de los psicólogos clínicos que ya lo son. Aunque hay algunas regulaciones legales al respecto, están todavla poco elaboradas en general. En las especialidades médicas, la industria farmacéutica es la que, con contadas excepciones, está llevando la iniciativa, ya de forma directa, ya sea participando, decisivamente en muchos casos, en la financiación de las actividades de formación continuada que ponen en marcha las diversas sociedades científicas vinculadas con las distintas especialidades. En el caso de la Psicología Clínica no hay prácticamente regulación alguna, y son las sociedades científicas las que están haciendo el esfuerzo de poner en marcha y al alcance de los psicólogos clínicos actividades de formación continuada. Pero como es obvio, la financiación aquí corre a cargo del interesado en su mayor parte, y tampoco hay establecidos controles de calidad de lo que se oferta. En mi opinión, este es un aspecto de especial trascendencia, al que la Universidad no debería renunciar en absoluto sino, bien al contrario, participar de manera activa. Quizá el nuevo marco de los futuros estudios de post-grado represente una buena oportunidad para ello.

Una vez recordados algunos de los elementos cruciales de nuestra historia y puesta de manifiesto la situación de la psicología clínica en nuestro contexto actual, ha llegado el momento de abordar algunos problemas derivados de, o relacionados con, el modelo dominante para la formación de profesionales de la psicología, con una referencia especial a la psicología clínica.

\section{SOBRE EL MODELO DE FORMACIÓN DEL PSICÓLOGO CLÍNICO COMO UN CIENTIFICO-PRACTICANTE}

No hay nada tan práctico como una buena teorla (J. Jungman). La teorla es asosinada tarde o temprano por la experiencia (A. Einstein). La experiencla es maravillosa: nos permite reconocer un error cada vez que lo cometemos (F.P.Jones)

Richard M. McFall, en su Manifesto for a Science of Clinical Psychology (1991) afirmaba lo siguiente: "The dichotomy between 
science and practice is the classic one-the one codified in the Boulder Model of clinical training with its hyphenated characterization of clinical psychologists as ascientist-practitionersm. The implication commonly attributed to the hyphenated Boulder Model is that there are two legitimate types of clinical psychology: clinical science and clinical practice".

Lo que McFall denuncia es algo que probablemente no estaba en la mente de quienes diseñaron el modelo de Boulder, que sigue siendo el marco de referencia para el diseño de los planes de formación de los psicólogos clínicos (y, en general, de la formación profesional de los psicólogos): el guión entre las dos palabras, ciencia y práctica, no se ha tomado como unificador sino como separador o diferenciador de dos modos diferentes de hacer en psicología clínica. De ahí que la primera consecuencia palmaria de la aplicación del modelo de Boulder a la formación de los psicólogos clínicos sea la consideración de la psicología clínica como una especie de hidra bicéfala: la científica y la aplicada. La primera cabeza se dedica a generar conocimiento, la segunda a gestionarlo, es decir, a aplicarlo sin participar en su gestación, o haciéndolo solo de forma ocasional y marginal. De ahi que McFall concluya que el modelo Boulder ha tenido como consecuencia final que haya dos formas de "hacer" psicología clínica, igualmente válidas, importantes, y necesarias: una científica y otra aplicada ${ }^{5}$.

Si admitimos de manera acrítica esta dicotomía, puede que estemos admitiendo a la vez que: a) hay una forma de hacer psicología clínica, la aplicada, que no necesita definirse como "científica"; b) hay otra que no necesita "preocuparse" por la aplicación de sus conocimientos, su puesta en práctica, su contrastación con la rea-

5. Esta diferenciación remite a su vez a otra más amplia: ciencias básicas versus ciencias aplicadas, y desde ahl, Investigación básica versus aplicada. No voy a extenderme aquI en ese debate por dos razones: una, porque me parece insustancial y bastante ficticio, a la luz de los actuales desarrollos del conccimiento clentfico; otra, porque me parece si cabe más ficticio cuando se aplica a la psicología. Toda Investigación cientfíca surge como necesidad de responder a un Interrogante, que puede ser més o menos importante, 0 necesario, o urgente, resolver, pero que en todo caso es en sl mismo aplicado a algo o, quizá, planteado por alguien pare resolver alga. Y lo que caracteriza el modo de responder del cientifico, ea "aplicado" o "basico", si es que quiere mantener la dicotomia, no es otra cosa que los procedimientos de los que se sirve para elaborar sus respuestas. En todo caso, podemos hablar de buena práctica cientifica versus mala, equivocada, 0 inútil. 
lidad. Pues bien: no me parece que esta dicotomía sea admisible de ningún modo. Ni creo que se pueda hacer una psicología clínica no científica (pues entonces no debería catalogarse como psicología clínica), ni creo que se pueda defender una psicologfa clínica que no tenga en cuenta el contexto social, o si se prefiere, los problemas de salud y enfermedad para los que debe aportar soluciones factibles y sobre los que debe estar en permanente interrogación. No olvidemos nuestra historia, no releguemos al cajón de las curiosidades el legado de los Pinel, Tuke, o Dix, esos nuevos cientificos que, como recordaba en la introducción, fueron los promotores de un nuevo modo de hacer ciencia según la cual el científico se implica de manera activa en el mundo social en el que vive. En cuanto a la psicología clínica aplicada, no reconocer de entrada que es una actividad científica, da pie a considerar que puede desarrollarse al margen de la ciencia, o en el peor de los casos, que es posible la existencia de alguna forma de psicología clínica no científica.

No obstante, puede que haya quien se plantee que aunque todo este discurso está bien e incluso es defendible, tiene poco que ver con la realidad, porque el psicólogo clínico aplicado se ve obligado en muchos casos a dar respuestas ante problemas que la investigación en psicología clínica no se ha planteado todavía. Y que, mientras esas respuestas lleguen, debe confiar en su intuición, su experiencia, o su buen juicio. Ante este tipo de argumentos, sin duda bienintencionados, se me ocurren algunas objeciones. No obstante me ceñiré únicamente a algo que ya comenté antes (véase la Nota 2): la ciencia, la investigación científica, no se caracteriza por hacerse preguntas para intentar responderlas. Eso es lo que caracteriza a los seres humanos en general. Lo que distingue el razonamiento científico del no científico es el modo en que se elaboran las respuestas. $Y$ mientras estas llegan, simplemente debemos admitir que no tenemos respuesta. Confiar en la intuición, en la experiencia, el buen juicio (clínico o no), para intentar responder a un problema de salud mental, para solventarlo de manera adecuada, es cuanto menos temerario. ¿O es que a cualquiera de nosotros se le ocuriría confiar en la intuición de un médico, y no en sus conocimientos científicamente fundamentados, para que nos extipara un tumor?. 
Reconozco que la argumentación y el ejemplo que acabo de poner pueden resultar exagerados, y hasta un punto demagógicos, pero son útiles para ilustrar lo que quiero decir: el argumento de que el psicólogo clínico aplicado no puede esperar a que la psicología clínica científica le de las respuestas porque debe responder rápidamente a los problemas que se le plantean, esconde dos supuestos peligrosos: primero, que el psicólogo clínico aplicado debe ser capaz de resolver cualquier problema de salud y enfermedad mental que se le plantee, independientemente de cuál sea el nivel de sus conocimientos como científico, o los de la psicología clínica, lo que a su vez, implica una temeraria carencia de autocrítica y auto-reconocimiento de los propios límites (y de los límites de su disciplina); y segundo, que es legítima una práctica de la psicología clínica que no esté científicamente fundamentada, puesto que prima la necesidad de dar respuesta "urgente" a un problema, por encima de lo razonablemente justificada que esté desde el punto de vista del conocimiento científico disponible en ese momento.

En sintesis: cualquier actividad profesional que desarrolle un psicólogo clínico debe estar firmemente anclada en los conocimientos cientificos disponibles hasta ese momento, y por tanto, es responsabilidad de cualquier clínico asegurarse de que aquello que prescribe y realiza en la práctica, es científicamente válido y aceptable. De no hacerlo asl, su práctica deberla considerarse ilegitima, $y$ en lugar de hablar de ciencia psicológica estarlamos ante una pseudociencia. En palabras de McFall (1991) "We simply cannot afford to purchase superficial tranquility at the expense of integrity". El dilema de la "urgencia" en ofrecer una respuesta, es simplemente tramposo. Ante la urgencia caben dos posibles respuestas, igualmente válidas: la primera, reconocer que no se sabe cómo responder, que como psicólogo clínico no se dispone todavía de una buena respuesta para el problema que, por ejemplo, nos plantea un paciente; y la segunda, que la respuesta, la solución o el remedio que se puede proporcionar, no está todavía suficientemente probada en términos de su validez y utilidad reales, es decir, lo que toda la vida hemos entendido como "en fase de estudio o en fase de investigación". Es decir, que estamos obligados a que el destinatario de nuestra actividad sepa con claridad meridiana, que lo que por ahora 
le podernos ofrecer no es algo que esté exento de riesgos, que no sabemos todavía cuál es su utilidad real, porque se haya todavía en tase de estudio y validación. Esto que es tan obvio, que tan legítimamente reclamamos como ciudadanos ante cualquier producto, y más si ese producto tiene que ver con nuestra salud, no es algo que esté presente en nuestra actividad cotidiana como psicólogos clínicos.

Otro problema relacionado con la formación es la ausencia de referencias a la necesidad de promover en los psicólogos en formación una actitud de auto-crítica constructiva y cuestionamiento constantes, en términos científicos, que incidan en la necesidad e importancia de establecer controles sistemáticos sobre la calidad de sus actividades y productos. No hay (o yo no los he encontrado) referencias al aprendizaje de criterios para evaluar la calidad de la actividad (clínica o en cualquier otro ámbito profesional). Dicho de otro modo: se enfatiza la necesidad de "aprender mediante la práctica", pero no se incluyen además descriptores que hagan referencia a la puesta en práctica sistemática de procedimientos de evaluación de la calidad de lo que se practica (y de lo que se aprende). Pelechano ya se refirió a esto mismo hace unos años cuando afirmaba "ni todo vale; ni todo lo que vale, vale lo mismo; ni vale de la misma manera" (Pelechano, 1996, p. 174,). En el contexto de la psicología clínica, control de calidad es prácticamente sinónimo de evidencias de utilidad y validez. Esto es, que los servicios que ofrecen y dispensan los psicólogos clínicos deben haber demostrado previamente su utilidad y validez según las reglas y leyes del conocimiento científico disponible. Si un psicólogo clínico ofrece servicios que no disponen de un apoyo empírico razonable, o por ponernos en lo peor, que no disponen de apoyo empírico alguno, entonces estamos fracasando en la aplicación de los controles de calidad mínimos exigibles a todo conocimiento y actividad científicas. Y si una organización profesional y/o académica no se toma en serio esta tarea, tendrá graves dificultades para lograr el respeto y reconocimiento de la sociedad, y a la larga, de los mismos profesionales a los que representa.

Ejemplos de a lo que me refiero los hay, y muy variados: no hay más que echar un vistazo a las muchas publicaciones profesionales y científicas a las que todos tenemos acceso, o a los tablones de 
anuncios de nuestras Facultades, para constatar la cantidad de cursos y cursillos de cualquier tipo y condición que se ofrecen a los estudiantes y a los profesionales, sin que exista ningún control de calidad previo sobre la veracidad (científica) de lo que se oferta por parte de las organizaciones y organismos responsables que consienten en darles publicidad. Aquí sl que creo que tendríamos que aprender mucho de las leyes del mercado. Aqui sí que tendríamos que ser bien estrictos en la aplicación de nuestro código deontológico. Porque no estamos "vendiendo" cualquier cosa, estamos ofreciéndonos como expertos en el diagnóstico, investigación, prevención, y tratamiento de la salud y la enfermedad mentales. O eso, al menos, es lo que decimos que somos y hacemos.

La necesidad de integrar la auto-evaluación de la calidad de nuestras actuaciones en la práctica clínica y en la formación de los psicólogos clínicos, no es algo nuevo. J. Rotter lo expresó con claridad hace ya algunos años: "Most clinical psychologists I know would be outraged to discover that the Food and Drug Administration allowed a new drug on the market without sufficient testing, not only of its efficacy to cure or relieve symptoms, but also of its short term side effects and the long term effects of continued use. Many of these same psychologists, however, do not see anything unethical about offering services to the public-whether billed as a growth experience or as a therapeutic one-which could not conceivably meet these same criteria" (Rotter, 1971, p. 1). Y avisaba de un riesgo que se corría si los psicólogos clínicos no nos tomábamos en serio este problema y este reto: "If psychologists are not more active and more explicit in their evaluation of techniques of intervention, they will find themselves restrained from the outside (...) as a result of their own failure to do what ethical and scientiflc considerations require". (p. 2). Me parece que no podemos correr el riesgo de "quedamos fuera", aunque solo sea porque entonces poco "mercado" nos iba a quedar.

Ligado con todo lo anterior, está la sensación de omnipotencia que cotidianamente podemos constatar en cuanto a las posibilidades de actuación científica y profesional de los psicólogos clínicos, hasta el punto de parecer que todos servimos para todo, que somos capaces de todo, y que podemos solventar cualquier problema de salud mental que se nos ponga por delante: desde el tratamiento de una 
enuresis infantil hasta la rehabilitación de una toxicomania, pasando por la resolución de un problema de pareja, el tratamiento de una crisis de ansiedad, o la reintegración a la normalidad de las funciones cognitivas superiores en un accidente cerebro-vascular. Esta actitud acrítica sobre lo que podemos y sabemos es enormemente perjudicial y peligrosa, no solo para nosotros como colectivo, sino sobre todo para nuestros clientes ${ }^{6}$.

Es verdad que las razones de semejante versatilidad son muchas, y no todas son atribuibles al colectivo de psicólogos clínicos. Pondré un ejemplo muy concreto: la actividad profesional que un psicólogo clínico se ve obligado a desarrollar en un Centro de Salud Mental del Sistema Nacional de Salud (y en muchos casos también, en el ámbito de la práctica privada). La especialización en esos centros es, hoy por hoy, prácticamente imposible: salvo en contadísimos casos, la mayoria de estos profesionales se ve obligado a tratar como mejor pueda y sepa cualquier problema de salud mental para el que se requiera su intervención. No obstante esta realidad, no podemos obviar el por qué se ha llegado a esta situación. A mi entender, la psicología clínica ha cometido desde el principio un error monumental: hiper-vender sus posibilidades reales. En parte por eso no podemos culpar sólo a la Administración, ni menos aún a los consumidores de nuestros servicios, por el exceso y la variedad de

6. Esta indefinición de competencias y capacidades afecta no solo a los psicólogos clínicos sino a la psicología en general, y de manera muy especial a los distintos ámbitos profesionales de los psicólogos, como ya mencioné en otro apartado. Asl, no es intrecuente encontrarse con debates sobre si un psicólogo educativo puede proporcionar un tratamientos psicológico específico para tratar un trastomo mental que presenta un escolar, o si un psicólogo dedicado a la selección de personal está capacitado para hacer diegnósticos y tratamientos relacionados con la salud mental de los trabajadores de una empresa. No voy a entrar aquí en semejante cuestión, pero no me resisto a apuntarlo como indicador de la indefinición de roles y capacidades en la que nos estamos moviendo en este país, que desde luego no se produce en los de nuestro entomo. Es evidente que todo psicólogo está capacitado por ley (como lo está cualquier médico recién licenciedo) para realizar cualquier actividad relacionada con su ámbito prolesional: desde una selección de personal, hasta aplicar un tratamiento psicológico específico para un trastomo delirante, o un prograna de rehabilitación de un esquizofrénico crónico, y así hasta el infinito. La pregunta es si semejante "amplitud" de capacidades es posible y éticamente sostenible. La pregunta es si admitirlamos tal tipo de funcionamiento en un médico, por poner el ejemplo más obvio. 
peticiones de solución que se nos plantean. No podemos culparles de que piensen que somos capaces de resolver cualquier cosa que nos pidan. Pero al mismo tiempo, creo que no podemos seguir con esta desmesurada oferta sin poner remedio. $Y$ el remedio es tan simple como reconocer públicamente que es lo que podemos y sabemos hacer, y qué no. Y eso pasa ineludiblemente por, al menos, tres cosas: una, formar a los psicólogos clínicos en el reconocimiento profundo de sus límites, en potenciar su actitud crítica como científicos; dos, explicar a la sociedad en qué podemos y no podemos ayudar; $y$, tres, demandar a la Administración el mismo trato que dispensa a otros facultativos sanitarios, potenciando las posibilidades de especialización de los psicólogos clínicos en alguno de los cada vez más complejos ámbitos de la psicología clínica para los que la investigación está demostrando con absoluta claridad y validez las posibilidades de actuación eficaz y eficiente de los psicólogos clínicos.

Puede que algunos se planteen que, si actuamos así, es probable que nuestros potenciales consumidores busquen solución en otros ámbitos distintos y, lo que es peor, menos preparados que nosotros para proporcionarles una ayuda eficaz. $Y$ que para evitar que esto llegue a suceder, con los peligros que puede entrañar para la salud mental de estas personas, es mejor que hagamos lo que podamos. De nuevo es éste un argumento bienintencionado, pero falaz. El que haya consumidores que estén dispuestos a aceptar antes una mentira que una verdad, no justifica que mintamos. Precisamente porque los destinatarios de nuestra actuación profesional son personas casi siempre extremadamente vulnerables, pues no debemos olvidar que estamos tratando con la salud mental, estamos obligados a ser tan estrictos como sea posible en la aplicación de las máximas garantías éticas y de responsabilidad en el desarrollo de nuestra actuación, en la prestación de nuestros servicios.

No obstante, es verdad que ante este tipo de problemas muchos psicólogos clínicos se plantean algo tan razonable como lo siguiente: ¿y en qué quedaría mi capacidad de actuación si únicamente me limito a dispensar aquellos tratamientos, a realizar aquellas intervenciones, que han demostrado su eficacia sobre la base de la evidencia científica disponible?. Y aún más, ¿qué debo entender por evidencia 
cientifica disponible?. La respuesta fácil es la que venimos observando en los últimos años: en el ámbito de la clínica, la evidencia disponible son los tratamientos empíricamente validados. Pero las cosas no son, a mi entender, tan sencillas como eso. En primer lugar, porque lo que hoy es una "evidencia" en el contexto de la clínica, puede dejar de serlo en cualquier momento, como sucede en cualquier ámbito del conocimiento científico. El estado de los conocimientos asentados en la psicologla clínica es todavía precario y cambia con rapidez. Por tanto, volcar todos nuestros esfuerzos formativos en que los psicólogos clínicos conozcan y apliquen únicamente aquellos procedimientos que han resultado estar "empíricamente validados" (lo que se ha dado en llamar psicología basada en la evidencia), puede dar como resultado un entrenamiento en la obsolescencia (McFall, 1991) 7 . Esto no significa que no haya que esforzarse y empeñarse en enseñar estos procedimientos $y$, aun más, en exigir su aprendizaje: lo que quiero decir es que hacer sólo eso no es suficiente o, mejor, que no es LA solución. En segundo lugar, porque si el psicólogo clínico solo se dedica a poner en práctica, a gestionar, lo que otros han desarrollado, estamos abocados a caer en la trampa de la dicotomía con la que comencé este apartado: ciencia versus aplicación.

Por lo tanto, la respuesta es otra. Creo que lo que verdaderamente nos está faltando en el diseño curricular de los futuros psicólogos clínicos (y de los que ya lo son) es el entrenamiento

7. La gestión adecuada del conocimlento explicito en psicologia clínica, sigue siendo un terna capital, pendiente de solución. Nuestro reto aqul, sl 80 me permite simplificar, no es tanto producir más información, sino generar respuestas pertinentes que, articuladas convenientemente, facilten la toma de la mejor declabon posible ante una situación concreta. Y esto no es una tarea fácil. Nuestras revistas y libros publican una ingente cantidad de información cada día, en muchas ocasiones redundante cuando no contrapuesta, de calidad desigual, y ante la cual el clínico se pregunte, no sin razón, cuál es su utilifad real. Además, en muchos casos esa información no es tácilmente acceslble o no siempre se encuentra disponible en aquellos lugares en donde más ee necesita, esto es, en el lugar mismo on que el clínico debe tomar una decisión. En otras ocasiones, la tarea mecánica de acceso a la Información de calidad interrumpe la actividad clínica en un entomo de trabajo las más de las veces saturado. En definitiva, creo que estamos ante otro problema todavla poco estudiado, para el que no tenemos soluclones, y que debemos abordar con urgencla. 
profundo y permanente en una actitud cientifica, que consiste básicamente en lo siguiente:

1. Conocimiento exhaustivo y en permanente actualización de las evidencias acerca de los procedimientos disponibles para resolver un problema específico.

2. Capacidad de reflexión crítica para valorar la validez y utilidad de las aportaciones disponibles.

3. Auto-conocimiento de las propias capacidades y limitaciones para desarrollar el mejor programa posible en las mejores condiciones posibles, $y$

4. Sometimiento sistemático a la evaluación externa de la propia actividad por parte de los pares.

$Y$ todo esto sólo es posible si el psicólogo clínico se instala, por asi decir, en una actitud de formación continua, en la que no solo debe dedicar una parte sustancial de su tiempo a seguir adquiriendo conocimientos, sino que además debe estar dispuesto a evaluar críticamente su desempeño, por todos los medios a su alcance. Tomarse en serio este planteamiento evitaría entre otras cosas, el riesgo del exceso de "creatividad" científica que a menudo observamos en la clínica, y que tan malas consecuencias puede tener ( $y$ de hecho tiene) en nuestra credibilidad como científicos. Ante las quejas de que un excesivo cientificismo recorta la creatividad, simplemente diría lo siguiente: si creatividad clínica significa hacer lo primero que a uno se le ocurra, dejar volar la imaginación, pinte un cuadro. Pero no se le ocurra emplear la creatividad para tratar un trastorno mental. No sé qué pensarán ustedes, pero cuando yo busco la actuación de un profesional, quiero que actúe como un profesional. Lo último que espero y deseo es que sea creativo conmigo, y menos aun cuando se trata de mi salud. Ahora bien: si creatividad clínica significa desarrollar y poner a prueba de manera sistemática y ordenada, es decir, siguiendo los métodos propios de la investigación científica, nuevos tratamientos psicológicos, o nuevos métodos de diagnóstico, o nuevas teorías explicativas sobre una dolencia particular, bienvenida sea. Pero recordemos que una de las marcas de contraste que define la actividad científica es la comparación con lo establecido y probado: sin un conocimiento profundo de los métodos adecuados para proceder a esa comparación y de 
los contenidos con los que comparar, no estamos en el camino correcto, no estamos siendo científicamente creativos, simplemente estamos incumpliendo nuestro compromiso ético fundamental.

Para terminar, creo que debemos hacer un esfuerzo colectivo por convencernos de que si no nos marcarnos metas claras como científicos, si no nos empeñamos en impregnar los curricula formativos de los psicólogos clínicos de una actitud científica, tenernos un negro futuro por delante. El psicólogo clínico es un científico que debe ser capaz de conocer y explicar con claridad qué servicios y productos de salud es capaz de suministrar a la sociedad, qué beneficios pueden derivarse de su desempeño profesional y en qué evidencias sustenta sus afirmaciones. Debe buscar la excelencia en su desempeño, debe ser capaz de contrastar lo ya sabido con lo nuevo, y debe exponerse a la crítica y evaluación sistemáticas como medio para evaluar la calidad de su actuación. Por lo tanto, cualquier programa de formación en psicología clínica debe tener como criterio rector la integración científica de la teoría, la investigación, y la aplicación práctica de los conocimientos.

\section{PENSANDO EL MAÑANA}

Las utoplas son vendades prematuras (A. De Lamartine)

Cuando en 1896 Witmer propuso ante sus colegas de la APA la creación de una nueva disciplina psicológica que denominó "Psicología Clínica", tan solo consiguió "una ligera elevación de párpados por parte de unos pocos de sus miembros más antiguos", si hacemos caso del relato de su amigo J. Collins. Después de todos estos años, es de suponer que nuestros colegas psicólogos se hayan acostumbrado ya a nuestra presencia y hagan algo más que levantar ligeramente los párpados cuando planteamos nuestros problemas y nuestros logros. Entre otras muchas cosas, porque la Psicología Clínica ha alcanzado la madurez y eso es un hecho incuestionable. La niñez desorientada y la adolescencia desnutrida y tempestuosa que Watson (1953) atribuyera a la Psicología Clínica, han dado paso a un estado de madurez, en el que se ha consolidado como profesión con entidad propia dentro del marco general de la ciencia psicológica. 
Además, una parte sustancial de la investigación que actualmente realiza la Psicologia en su conjunto recae sobre los aspectos clínicos. Y la mayoría de los estudiantes que se acercan a nuestras facultades, tienen la intención de convertirse en psicólogos clínicos.

No obstante, hay todavía muchos problemas para los que deberíamos ser capaces de encontrar una solución, siquiera tentativa. Uno de ellos se refiere al debate entre psicoterapeutas y psicólogos clínicos, como si se tratase de dos conjuntos diferentes de profesionales. El debate se plantea ligado muchas veces a ciertos tipos o modalidades de entrenamiento psicoterapeútico especifico, como es el caso del psicoanálisis. En mi opinión, la polémica se basa en la confusión radical entre una profesión (la Psicología Clínica) y una de las tareas típicas de un psicólogo clínico, la psicoterapia. A su vez, ésta última es una disciplina típicamente psicológica, al igual que lo son el psicodiagnóstico, la personalidad, la psicometría o la psicopatología. La Psicología Clínica en tanto que profesión, requiere un amplio entrenamiento en muchas disciplinas psicológicas, entre las que sin duda se incluye la psicoterapia. Lo que sucede es que un psicólogo clínico puede especializarse a la hora de desarrollar siu trabajo en una o más de las áreas y/o disciplinas en las que ha recibido entrenamiento (diagnóstico, investigación psicopatológica, práctica y/o investigación en psicoterapia, trabajo individual, trabajo con grupos, administración, educación, etc). $Y$ por supuesto es probable que para practicar adecuadamente algunos tipos especificos de psicoterapia, deba recibir un entrenamiento adecuado, una vez completada su formación integral como psicólogo clínico.

En definitiva, me parece que se trata de un debate equívoco y que está mal planteado. Parafraseando a Heinz Werner, cuando hablaba del desarrollo de los organismos vivos: un psicólogo clínico es un organismo vivo, lo que significa que está en continuo desarrollo y crecimiento. $Y$ todo proceso de desarrollo avanza progresivamente desde unos estadios iniciales de escasa diferenciación hacia otros de una especialización cada vez mayor. Pero el organismo debe ser capaz de integrar en un todo coherente esos avances y especializaciones; de lo contrario, corre el peligro de desintegrarse.

De un orden diferente, pero no menos complejo, es la creciente especialización a la que el psicólogo clínico se está viendo abocado. 
En el apartado anterior ya hice alguna alusión al respecto, que retomo ahora. El incremento de la complejidad del ámbito de actuación profesional de la psicología clínica se acompaña, como no podía ser de otro modo, de un aumento significativo de los conocimientos y la investigación sobre los procesos de salud y enfermedad que afectan a las personas. No se requieren las mismas habilidades ni competencias, ni los mismos conocimientos (que además, crecen a un ritmo en ocasiones vertiginoso) para ejercer la profesión en función de la edad de la población diana: niños, adolescentes, adultos, mayores. Ni tampoco para trabajar con las necesidades que plantean las personas con trastornos de ansiedad, de personalidad, 0 depresivos, o de naturaleza psicótica. Del mismo modo que el tipo de intervención psicológico-clínica que se debe hacer cuando se trabaja en el campo de la rehabilitación del enfermo mental crónico, o de la del drogodependiente, dista notablemente de la que se requiere cuando se trabaja con personas que padecen enfermedades médicas diagnosticadas (cáncer, asma, cardiopatías, dolor crónico, enfermos terminales, etc.), en las que los aspectos psicológicos influyen tantas veces de manera crucial. Por no mencionar las necesidades de especialización para trabajar en el ámbito de la neuropsicología, ya sea al nivel del diagnóstico, ya del tratamiento y la rehabilitación. No se requiere el mismo tipo de habilidades para trabajar con grupos que a nivel individual. $Y$ así un largo etcétera. Esta creciente diversificación de campos de actuación especializada de calidad, plantea retos e interrogantes cruciales para la formación de los futuros psicólogos clínicos, puesto que amplía notablemente las necesidades de formación. Hay algunas voces que, ante este estado de cosas, reclaman la puesta en marcha de algo así como licenciaturas de psicologla clínica que, en un primer nivel (el correspondiente al grado) proporcione un panorama amplio de todas las posibilidades de intervención y desarrollo de la psicología clínica para, posteriormente, en un segundo y tercer ciclos proceder a la adquisición de competencias especificas en algún campo o área más concretos. Algunas universidades norteamericanas están de hecho dando pasos firmes en esta dirección. En mi opinión, no creo que este planteamiento tenga futuro, al menos a medio plazo, en nuestro contexto. $Y$ tampoco tengo claro que sea útil y válido para solucionar 
el problema de la creciente diversificación de la psicologla clínica. Pero, en cualquier caso, habrá que estar atentos al futuro y trabajar con perspectiva, si no queremos perder el rumbo de este todavía demasiado frágil navlo. Serla terrible que se cumpliera el famoso dicho de Thomas $M$. Jones: "Los amigos van y vienen, pero los enemigos se acumulan".

\section{BIBLIOGRAFÍA}

Asoclación Española de Psicologla Clínlca y Psicopatología (2004). Sobre el debate en tomo a la Ley de Cohesión y Calidad del SNS y la LOPS. Revista de Psicopatologla y Psicologla Clínica, 9, 71-78.

Asoclación Española de Pslcologla Clínlca y Pslcopatologla (2004b). Declaración por el desarrollo de la Psicología Clínica en España. Revista de Psicopatología y Psicologla Clínica, 9, 255-258.

Belloch, A. (1997). One hundred years of clinical psychology: roots, doubts, and hopes. En: R. Fuller, P. N. Walsh, y McGinley,P. (eds.). A century of Psychology: Progress, paradigms and prospects for the new millenium (págs. 85-106). Londres: Routledge.

Belloch, A. (2003). Licenciatura en Psicología y formación en psicología clínica: la situación actual. En: A.Espino y B.Olabarría (coords.) La formación de los profesionales de la salud mental en España. (p. 63-75. Madrid: AEN, Colecc. Estudios.

Belloch, A., o lbáñez, E. (1989). Psicología académica y psicología profesional en el campo de la clínica. Anuario de Psicologla, 41, 33-48.

Belloch A. y Olabarrfa B. (1994).Clinical Psychology in Spain. Applied Psychology, 43, 193-211.

Bernsteln, D.A. y Nletzel, M.T. (1980). Introduction to Clinical Psychology. Nueva York, McGraw Hill.

CarpIntero, H. (1989). El psicólogo en España. Notas histónicas sobre su desarrollo profesional. Papeles del Psicólogo, 36/37, 68-73.

Gerfleld, S.L. (1974). Clinical psychology: The study of personality and behaviour. Nueva York, Aldine.

Korchln, S.I. (1983). The history of clinical psychology: a personal view. En M. Hersen, A.E. Kazdin y A.S. Bellack (eds.). The Clinical Psychology Handbook (p. 5-19). Nueva York, Pergamon Press. 
McFall, R.M. (1991). Manifesto for a Science of Clinical Psychology. The Clinical Psychologist, 44, 75-88.

Olabarría, B. (2004). Avatares de la psicología clínica, especialidad sanitaria de la psicología. Revista de Psicopatologia y Psicología Clínica, 9, 163-174.

Palaclos, A.J. (2004). Sobre la profesión de psicólogo clínico: consideraciones actuales y retos futuros. Revista de la Asociación Española de Neuropsiquiatria, 24, 139-147.

Pelechano, V. (1996). Psicología clínica, psicología de la salud, y la búsqueda del santo grial. En V. Pelechano (ed), Psicología Clínica y/o Psicologia de la salud (p.163-204). Valencia, Promolibro.

Pllgrlm,D. y Treacher, A. (1992). Clinical Psychology observed. Londres, Routledge.

Relsman, I.M. (1976). A History of Clinical Psychology. Nueva York, Irvington.

Rotter, J.B. (1971). On the evaluation of methods of intervening in other people's lives. The Clinical Psychologist, 24, 1-2.

Santolaya, F., Berdullas, M. Y Fernández, J.R. (2002). Análisis del desarrollo de la psicologia profesional en España. Papeles del Psicólogo, $82,65-82$.

SIguán, M. (1978). La enseñanza universitaria de la psicología en España. Anuario de Psicologia, 19, 125-137.

Stone, M. (1985). Shellshock and the psychologists. En W.F. Bynum, R. Porter y M. Shepherd (eds.), The Anatomy of Madness. Londres, Tavistock.

Watson, R.I. (1953). A brief history of clinical psychology. Psychological Bulletin, 50, 321-346. 